\title{
Nursing students' perceptions of desirable leadership qualities in nurse preceptors: A descriptive survey
}

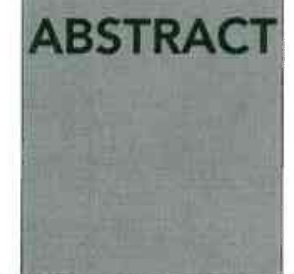

KEYWORDS

nursing; nursing education; clinical leadership; preceptorship; nursing students; clinical practice
There is a paucity of literature examining the context of leadership within the clinical preceptor/undergraduate nursing student relationship and the relevance of this to the clinical learning environment. This study used a mixed methodological survey approach to explore the leadership qualities in nurse preceptors that are considered desirable and contribute to positive practicum experiences from the perspective of 23 undergraduate nurses. Findings showed students both want and need leadership from their preceptors in order to develop psychomotor skill competency and to experience orientation to the real world of nursing care. Gaining insight into the leadership qualities that students perceive as desirable to enhance the practical experience is vital since that practical experience is viewed as the 'making or breaking' of many students and influences retention in undergraduate education and within the profession post registration.

Received 12 April 2007

Accepted 26 June 2007

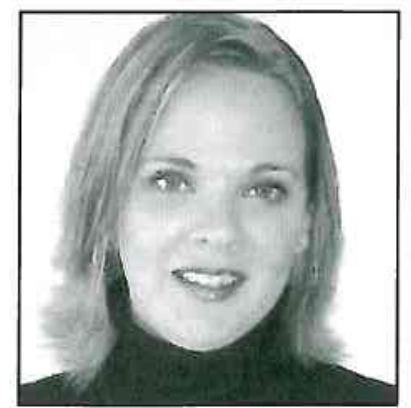

Melanie Zilembo PhD Candidate Edith Cowan University

Perth WA, Australia

\section{INTRODUCTION}

7 he current global shortage of registered nurses (RNs) across all specialties has implications not only for patient care, but for the provision of education for the nurses of the future. These shortages are a world wide concern with noticeable reductions in the nursing workforce in the United States of America (USA), the United Kingdom (UK) and Australia

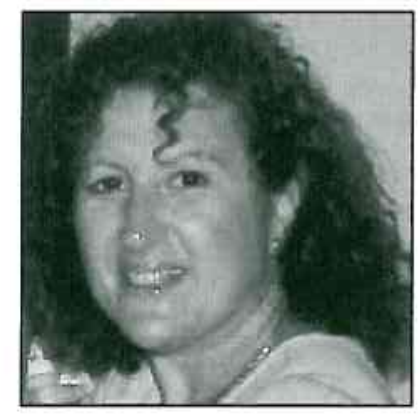

LeANne Monterosso Associate Professor Cancer Nursing Western Australia Centre for Cancer and Palliative Cầre Research Division of Health Sciences Perth WA, Australia Curtin University

(Australian Institute of Health and Welfare 2004; Australian Nursing Federation 2005; Dunn 2003). This is occurring in a climate where RNs are already challenged by a high level of demand on their services (National Review of Nursing Education 2002).

In Australia the shortage of qualified nurses affects both rural and urban centres (AIHW 2005; Dunn 2003; Firtko, Stewart \& Knox 
2005) and this issue is high on the political agenda. Nurses are the fastest ageing group within the health profession workforce and the average age of employed nurses increased from 39.3 years in 1995 to 42.2 years in 2001 (Australian Institute of Health and Welfare 2004). In 1999/ 2000 the national average attrition rate from pre-registration programs was $7 \%$ (National Nursing and Nursing Education Taskforce 2005). To address this shortage in Australia, it was estimated that between 10,182 and 12,270 new graduate nurses were required to enter the workforce in 2006 (AIHW 2005). The Australian Health Workforce Advisory Committee projected only 6,131 new graduates would enter the healthcare system, representing a shortfall of 4,051 nurses (AIHW).

Nursing education in Australia now comprises professional degree preparation in the higher education sector (Daly, Speedy \& Jackson 2000; Sellers \& Deans 1999). Practical experience is based predominantly on a model of education where students are partnered with RNs during clinical practice for supervision and guidance (Nurses Board of Western Australia 2004). This represents a dichotomy because many nurses are neither trained nor willing to accept the role. This creates a 'pot luck' system of education creating disparate clinical experiences for students and has been attributed as a causative factor for the theory-practice gap (White \& Ewan 1991).

In summary, previous research confirms that early practical experiences and relationships with clinical supervisors can shape a student's perceptions of the profession (Lofmark \& Wikblad 2001). Practical experience for undergraduate nursing students can provide a 'real world' nursing experience that will potentially reduce the 'reality shock' of the clinical setting as well as expose the student to both positive and negative behaviours exhibited by clinical staff (Australian Universities Teaching Committee 2002; Lockwood-Rayermann 2003). The relationships experienced by the students with clinical staff have been shown to 'make or break' the practical placement (Cahill 1996). Nurse preceptors can fulfil their role effectively by supporting students in their professional development and being responsive to students' needs (Dunn \& Hansford 1997). However, barriers such as increased workloads and patient acuity due largely to the nursing shortage (ANF 2005) lessen the amount of support that can potentially be provided and negatively impacts on students' learning experiences (Geraghty 2005). Cahill (1996) contends there is little evidence to show that preceptorship is effective as few studies have focussed on the needs and values of the students in this educational arrangement. Impressions of the nursing profession are formed early by undergraduate nurses and these attitudes tend to be long lasting (Lockwood-Rayermann 2003; Myrick \& Yonge 2002). This, together with the current climate of industrial unrest and a global nursing shortage underscored the need to explore the manner in which supervision and guidance is provided to students.

\section{LEADERSHIP DEFINED}

Leadership is distinguished by the interconnectedness between people, their relationships and influence (De Pree 1990). It encompasses concepts of influence, driving accomplishment, vision and embraces the values and attitudes of self and organisation. In short, leadership involves a process, which involves one person influencing others to accomplish objectives (Clark 1997). Morrison, Jones and Fuller (1997) define leadership simply as the ability to influence a group toward achievement of goals. Vandeveer (2006) extends this definition to propose that leadership is a catalyst that transforms potential into action and thus reality. Mahoney (2001) argues that all nurses need leadership skills and that leadership is inherent in the role of the nurse.

Transformational leadership (Burns 1978; Thyer 2003; Tichy \& Devanna 1990) is viewed as a leadership style that transforms those led 


\section{Cy Melanie Zilembo and Leanne Monterosso}

through inspiration to 'higher levels of motivation and morality'. Bass (1985) asserts that transformational leaders effect change in their followers by increasing their awareness of the values of the tasks they perform and by focusing on organisational goals rather than individual interests which activates higher order needs. Transformational leadership within nursing has been explored widely in the literature. Lett (2002) explored the concept of leadership in nursing and concluded that effective leadership results in improved patient care. Sofarelli and Brown (1998) undertook a large scale review of literature relating to leadership in the nursing profession and concluded that transformational leadership empowers nurses, which is a pivotal process in effecting organisational change.

Transactional leadership is based on the assumption that people are motivated by reward and punishment. The transactional leader sets clear expectations of what is required of the subordinate and the rewards offered for following orders (Changing Minds 2006). Research has shown that nurses are motivated to perform by both intrinsic and extrinsic rewards (Usher et al. 1999). Yet punishment, which is cited as a motivation to achieve, is not considered a motivating factor in any identified literature discussing leadership in the nursing profession.

Performance is an expected service in a transactional relationship. This may be simply in terms of the performance of a job in exchange for a salary. The concept of demand and supply in industry impacts greatly on the notion of reward and punishment (Changing Minds 2006).

Congruent leadership is an emerging theory that sits well with clinical leadership in the nursing profession. Stanley (2005: 132) defines congruent leadership as 'where the activities, actions and deeds of the leader are matched by and driven by their values and beliefs'. Like the transformational leader, the congruent leader inspires the led through embodying a quality of vision and being an effective communicator. Stanley (2005) found that the congruent leader often does not hold an official position of leadership, do not always hold positions as senior nurses, and are genuine carers that are able to critically think and prioritise their actions (Stanley 2005).

Another emerging leadership theory is that of authentic leadership, which asserts that, people generally wish to be inspired. People want to enrol in enterprises that engage their spirits as well as their minds (Bergeron 2002) and this embodies the uniqueness of the concept of authenticity and authentic leadership. The authentic leadership model makes use of whatever strategies may be apparent as long as they are congruent with values and beliefs that 'lead to positive action' (Bergeron 2002). Duignan and Bhindi (1997) argue that in order to become an authentic leader, the individual must undertake serious self-examination and be acutely aware of their own values, attitudes and beliefs.

This descriptive, two-phase, mixed method study used a survey to sample 23 pre-registration nursing students about their opinions of leadership in the clinical practice context.

\section{CONCEPTUAL FRAMEWORK}

The conceptual framework underpinning this study was adapted from a fusion of the synergy model of preceptorship proposed by Alspach (2006) and the synergy model for patient care described by Kerfoot (2002). An adapted model is proposed which considers patient care, leadership and nursing preceptorship as interrelated elements that contribute to the learner's clinical experience. The central concept of the adapted model assumes that nursing students (preceptees) experience clinical practice positively when the nurse preceptor demonstrates the desirable characteristics required of a nurse preceptor, including leadership (see Figure 1).

\section{ETHICAL CONSIDERATIONS}

This study was approved for implementation by the Edith Cowan University Human Ethics Sub 


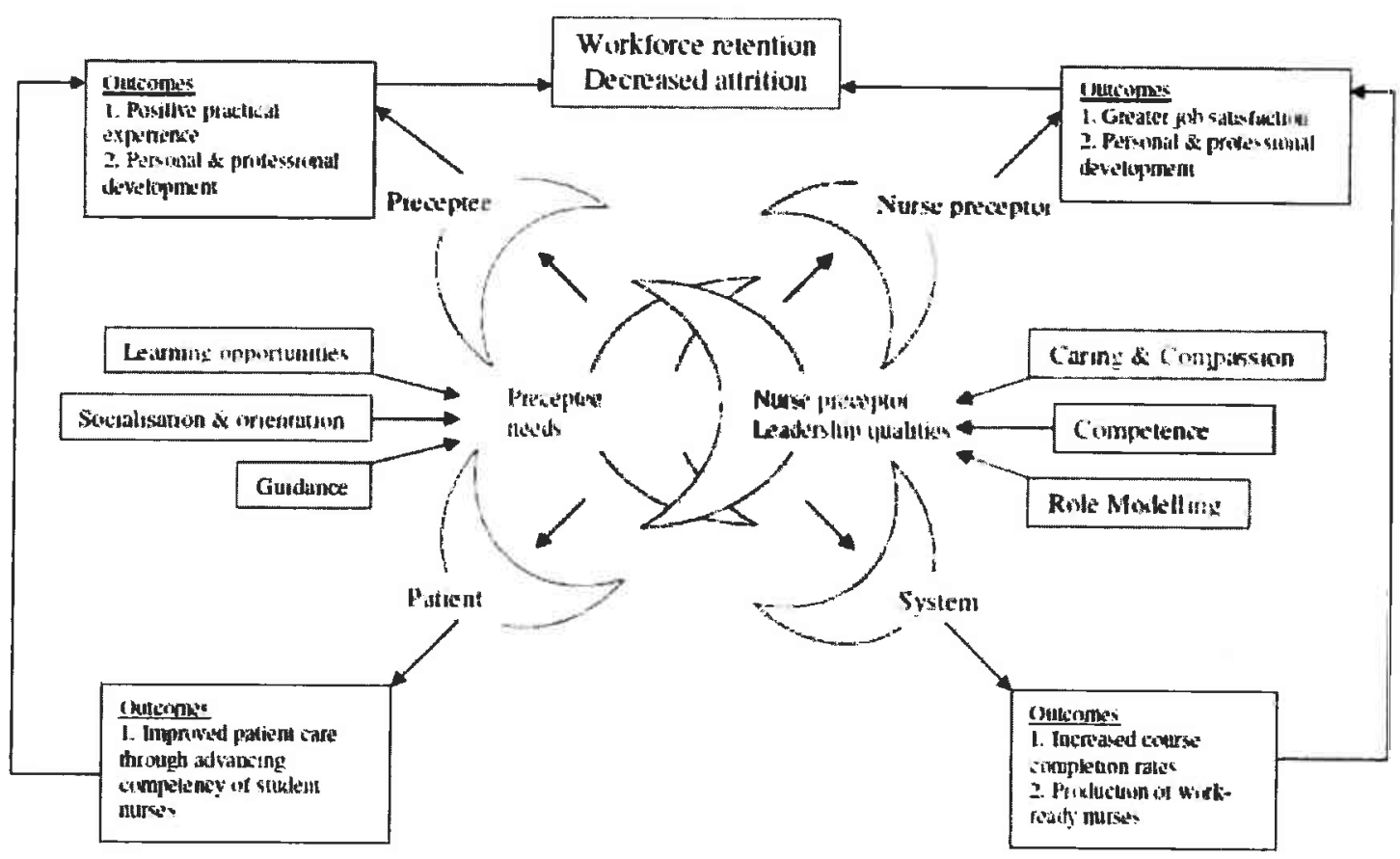

Figure 1: Proposed Synergy Model of PRECEPTORSHIP for LEARNing aNd CARE

Committee in June 2006. Ethical approval was granted on the provision that students were given adequate information and assured that declining to participate would not impact upon their course progress. No ethical issues arose during this study.

\section{Methods}

This study comprised two phases. In Phase 1 an instrument titled 'Qualities of Leadership Survey' was developed, and then pilot tested for clarity, apparent internal consistency and content validity. In Phase 2, the instrument was administered to a group of nursing students representative of the same group used for phase 1 .

\section{Setting}

Both phases of the study were undertaken within the largest undergraduate nursing school in Western Australia where 1200 students were enrolled in a pre-registration Bachelor of Nursing. This is a three year full-time course with six semesters of study (COGNOS 2006). Participants in both phases were selected from this population. Purposive sampling of students was undertaken using the following inclusion criteria:

- Enrolled in the Bachelor of Nursing (preregistration) course either a on a fulltime or part-time basis;

- Enrolled in the fourth" semester of the course;

- Enrolled in the Nursing Practice Four unit;

- Had completed a minimum of 200 hours of clinical practice.

Students enrolled in the second year of the preregistration course were excluded if they were not enrolled in the Nursing Practice Four unit, and/or semester four of the pre-registration course.

\section{Instrument}

Since no previously developed instrument was 
available, a questionnaire titled 'Qualities of Leadership Survey' was specifically developed for this study. The questionnaire comprised ten items of which four were related to demographic information, two focused on opinions of the importance of clinical leadership, and one item asked respondents to describe negative and positive aspects of their preceptored experiences. Item seven replicated a question that was used in an instrument developed by Stanley (2004) which explored 39 prescribed characteristics RNs associated with leadership. These characteristics were drawn evenly from literature relating to both transformational and transactional leadership. Preliminary face validity and content validity testing of Stanley's instrument showed a strong link between clinical nurse leadership and transformational leadership with $100 \%$ of respondents $(n=13)$ agreeing the characteristics of support, integrity and coping well with change were important. In adapting this item for the current study, fourteen of the original instrument characteristics were retained. Fourteen additional characteristics were drawn from literature relating to authentic and congruent leadership. Thus, the instrument comprised items according to the following four models of leadership: transformational, transactional, authentic and congruent.

\section{Phase one}

The 'Qualities of Leadership Survey' instrument was tested for clarity, apparent internal consistency and content validity in August 2006 using a questionnaire devised by the researcher to assess the following criteria:

1. Were the instructions clear?

2. Were any of the questions ambiguous?

3 . Were any topic areas omitted?

A group of seven undergraduate pre-registration Bachelor of Nursing students in the fourth semester of study were selected to participate in the validity testing. Respondents were selected from the context within which the original data was drawn in keeping with Aamodt's (1982) recommendation. Students fitting the inclusion criteria were approached prior to a lecture and given information regarding the study. Seven students agreed to participate. Consent was implied if the anonymous questionnaire was returned.

\section{Procedure}

A copy of the instrument, an information letter and a copy of the validity testing questionnaire was given to each of the seven students along with an addressed envelope for return of the completed questionnaire. Five questionnaires were returned ( $71 \%$ response rate).

\section{Results}

Responses indicated the items within the instrument were clear, non-ambiguous and relevant (100\% agreement rate). There were no recommendations for change or review, thus no further analysis was required and phase two was undertaken.

\section{Phase two}

\section{Sample}

Students meeting the same inclusion criteria for Phase One were approached. Consent was implied if the student returned the completed questionnaire.

\section{Procedure}

This Phase was undertaken between August and September 2006. An envelope containing an information letter, a questionnaire and addressed envelope was distributed to students in attendance at a pre-designated lecture. Students were asked to return the completed questionnaires in the addressed envelope the following week to the reception area of the nursing building where a fixed, locked box was located. One hundred and eight questionnaires were distributed and 23 were returned within the two week timeframe. Owing to a poor attendance at 
the initial lecture and a poor response rate, the researcher attended the same lecture two weeks later and repeated the above procedure. No further questionnaires were returned.

\section{Data analysis}

Numeric and categorical data from the completed questionnaires was entered into a SPSS version 12 database and analysed using simple descriptive statistics. Qualitative data from each open-ended item of the instrument was transcribed verbatim by the researcher. Responses from four open-ended questions were analysed using thematic analysis using three levels of analysis (level one coding for key words, level two coding for sub-themes and level three coding for main themes).

\section{Results}

\section{Sample characteristics}

Twenty-one students were female $(91.3 \%)$ and two were male $(8.7 \%)$. These figures were rep- resentative of demographic profiles of both the study university (COGNOS, 2006) and overall figures for Australian undergraduate nurses. Thirteen percent $(n=3)$ of respondents were aged less than 20 years, 17\% $(n=4)$ aged between 20-24 years, 52\% $(n=12)$ aged between 30-39 years, and $17 \%(n=4)$ were 40 years of age or more. The majority of respondents were aged between $30-39$ years $(52 \% ; n=12)$ which was higher than that of the study university and Australian wide average. According to The Australian Institute of Health and Welfare (AIHW 2003) data, many students entering undergraduate nursing programs are mature aged. In 1998, students aged 30-39 years accounted for $17.4 \%$ of student intakes (see Figure 2).

Forty seven percent $(n=11)$ of respondents reported their highest level of education was completion of Year 12. This was followed by $17 \%(n=4)$ respondents having attained a TAFE (Technical and Further Education) certificate level of vocational education. These four respondents were enrolled nurses.

60

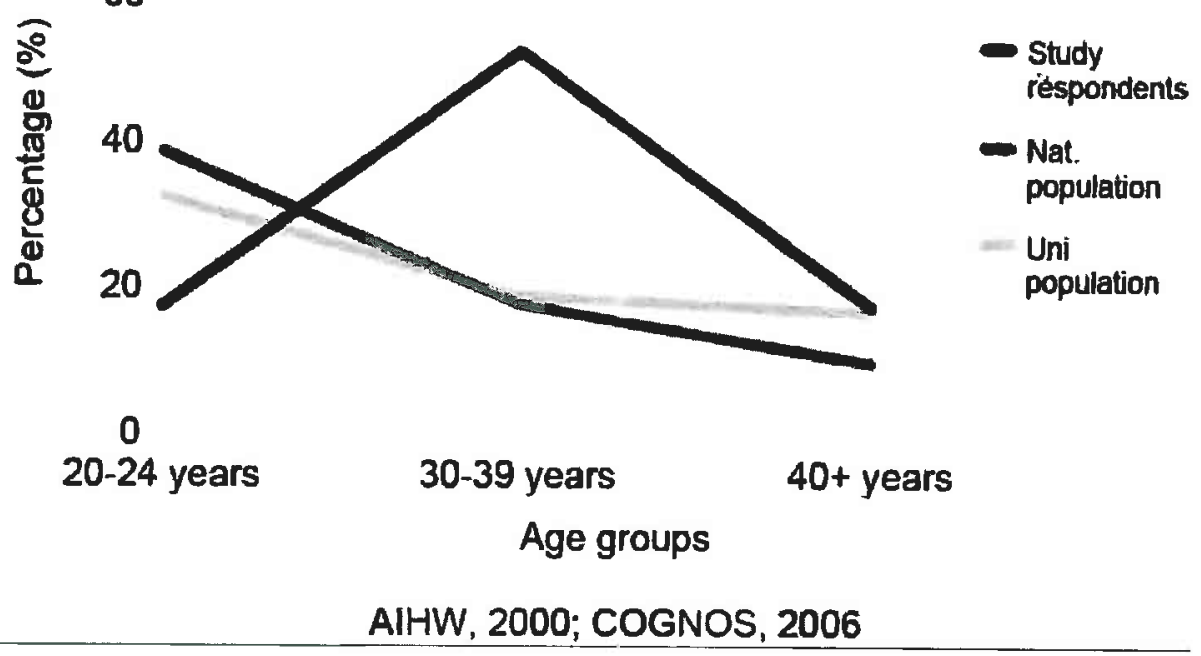

FiguRE 2: AGE DISTRIBUTIONS OF PARTICIPANTS 


\section{Qualities of leadership}

A total of $96 \%(n=22)$ respondents agreed that leadership was an important role of the clinical preceptor. The highest rated desirable characteristics in the item relating to leadership in nurse preceptors were clinical competence and purposefulness, both of which were rated by $100 \%$ $(n=23)$ of respondents. Characteristics of support, motivation, approachability, consistency, organisation and effective communication were all rated as desirable in relation to leadership in preceptored education by $96 \%(n=22)$ of participants. Characteristics rated as the least desirable leadership qualities were negotiation (56\%), analytical (52\%) and reward and punishment (30\%). (See Table 1.)

\section{Leadership and preceptors}

All respondents $(n=23,100 \%)$ provided a definition of clinical leadership in their own words. The following themes emerged from the data: competence and knowledge; the importance of teaching skills; and socialisation to the culture of nursing.

Thirty nine percent of respondents $(n=9)$ identified the importance of clinical competence and knowledge with leadership in preceptors. One respondent stated that a clinical leader was 'someone to learn clinical skills from years of experience' while another included the role of the preceptor as a teacher in his/her response by stating the definition of a clinical leader as 'someone who has the skills and knowledge to teach those who are learning'.

TAble 1: Qualities of leadership ( $\mathbf{N}=\mathbf{2 3}$ )

\begin{tabular}{|c|c|c|c|c|}
\hline Characteristic & Yes & Don't know & Don't care & No \\
\hline Purposeful & 23 & 0 & 0 & 0 \\
\hline Clinically competent & 23 & 0 & 0 & 0 \\
\hline Supportive & 22 & 0 & 0 & 1 \\
\hline Motivator & 22 & 0 & 0 & 1 \\
\hline Approachable & 22 & 0 & 0 & 1 \\
\hline Consistent & 22 & 1 & 0 & 0 \\
\hline Organised & 22 & 1 & 0 & 0 \\
\hline Effective communicator & 22 & 1 & 0 & 0 \\
\hline Inspires confidence & 21 & 1 & 0 & 1 \\
\hline Critical thinker & 21 & 2 & 0 & 0 \\
\hline Sets goals and targets & 21 & 1 & 0 & 1 \\
\hline Passionate & 20 & 0 & 0 & 3 \\
\hline Guided by principles & 19 & 4 & 0 & 0 \\
\hline Compassionate & 19 & 2 & 0 & 2 \\
\hline Inspirational & 18 & 2 & 0 & 2 \\
\hline Autonomous & 18 & 5 & 0 & 0 \\
\hline Self-disciplined & 18 & 4 & 1 & 0 \\
\hline Congruent & 16 & 5 & 0 & 0 \\
\hline Relationships valuable & 16 & 1 & 0 & 1 \\
\hline Visible & 16 & 3 & 2 & 1 \\
\hline Resource allocation & 15 & 6 & 0 & 1 \\
\hline Authentic & 15 & 7 & 0 & 0 \\
\hline Empowered & 15 & 8 & 0 & 0 \\
\hline Negotiator & 13 & 9 & 0 & 1 \\
\hline Analytical & 12 & 10 & 0 & 0 \\
\hline Reward/punishment & 7 & 5 & 0 & 10 \\
\hline
\end{tabular}


One respondent stated that 'having a good knowledge base and understanding of the student nurse's role and their scope of practice' enhances a leader's role.

Clinical leadership was seen as a means of developing professionally as a student and into the culture of the nursing profession. One respondent stated:

Clinical leadership is the ability to, or responsibility of imparting knowledge in enhance[ing] skill level while at the same time promoting personal growth of the student.

Socialisation within the nursing environment was reported in terms of 'fitting in' with the ward routines and staff. Forty-three percent of respondents $(\mathrm{n}=10)$ indicated that they felt the clinical leader was able to actualise a clinical environment conducive to these conditions for the student nurse. One respondent stated:

[the clinical leader] leads a team or individual so that they can develop their understanding, confidence and ability [and] also be able to support them emotionally and mentally by providing knowledge and resources that may be necessary and appropriate.

This point was also described by other respondents in terms of the clinical leader possessing 'an actively supporting attitude', 'expertise and guidance' and 'the ability to help in any way to assist a student to complete a practical rotation'.

The respondents within the study defined the meaning of leadership broadly, though all responses related explicitly to clinical leadership qualities that relate specifically to preceptored education.

\section{Discussion}

The key findings from this study indicate unanimous agreement that leadership is an important role of the nurse preceptor yet is a complex issue for students to negotiate in practice. Data showed respondents favoured a transformational approach to leadership style but identified the need for nurse preceptors to adapt to individual situations and each learner as having unique learning needs.

Lett (2002) explored the concept of leadership in nursing and concluded that effective leadership results in improved patient care. Sofarelli \& Brown (1998) undertook a large scale review of literature relating to leadership in the nursing profession and concluded that transformational leadership empowers nurses, which is a pivotal process in effecting organisational change. Trofino (1995: 48) examined the concept of transformational leadership from a global economics perspective and asserts that 'The transformational leaders will be persuasive, creative and intuitive, so as to enhance these skills in others and to nurture nursing leaders for the future'.

Transformational leadership is described as dynamic and capable of empowering change among individuals. Interestingly, transformational characteristics were favoured among the study respondents as desirable which led into deeper themes relating to educational needs and outcomes.

The major themes included interpersonal communication, integration of theory and practice, continuity of preceptor and psychomotor proficiency and were highlighted by participants as conducive and obtrusive factors existing within the preceptored model of clinical education.

\section{Interpersonal communication}

The respondents within this study highlighted the importance of a mutually positive working relationship with their preceptors in order to gain the most from the clinical placement. Qualities of communication skills, supportiveness and approachability were rated by $96 \%$ $(n=22)$ of respondents as desirable. Nurse preceptors who embodied and communicated these interpersonal skills were viewed as effective preceptors and clinical leaders. These findings concur with those from interdisciplinary research that has shown a positive interpersonal 
relationship between teachers and students results in an increased quality of learning (Hekelman et al. 1995; Hilliard 2000; Vaughn \& Baker 2004). The development of a positive working relationship between a nurse preceptor and student involves developing a mutual rapport (Geraghty 2005; Stevenson, Randle \& Grayling 2006) and communicating effectively and with mutual respect (Clay et al. 1999).

\section{Continuity preceptor}

Developing a positive interpersonal relationship is a timely process and unless a student is exposed to the same preceptor for a period of time, an effective working relationship is unlikely to be established. Continuity of preceptors was highlighted by fourteen respondents (61\%) as important for effective preceptorship experiences. This was further emphasised by eight respondents (35\%) who reported the difficulty associated with 'being passed from nurse to nurse' and the subsequent inconsistencies that arose with each nurse teaching and practising various tasks differently. The lack of continuity appeared to cause confusion for students who reported that working with a new preceptor was like 'starting over'. Geraghty (2005) examined the effectiveness of preceptorship within a Western Australian perinatal hospital and highlighted the difficulty preceptees have in building a rapport with a preceptor when allocated to work together on only one occasion. Anecdotally, this is a common scenario in the majority of teaching hospitals within Western Australia. One of the contributing factors to this situation is that many nurses in Australia work part-time. In 2003, 50\% of RNs in Australia worked less than 35 hours per week (AIHW 2004).

Respondents rated 'supportive' (96\%) and 'inspires confidence' (91\%) as highly desirable qualities in their nurse preceptors. These findings were reinforced by responses to the open ended questions citing a positive practical experience results from feeling confident and supported in clinical practice by the nurse pre- ceptor. Early positive socialisation experiences have been shown to improve retention rates of new nurses (Myrick \& Yonge 2002), which are issues of premium concern in an era of worsening nursing shortages at all levels of the profession. Therefore the lack of a conceptual framework to guide preceptorship may be a contributing factor to the difficulties expressed by the respondents in building rêlationships within the complex interactions of the nursing environment.

\section{Assimilating theory and practice}

Findings demonstrated that students view the practicum experience as the opportunity to contextualise theoretical learning within the practical setting. One respondent reported that she was 'able to consider a real patient case to give knowledge of relevant pathophysiology and pharmacology meaning within the context of that particular patient's condition'. Four respondents (17\%) identified the link between theory and practice as embedded within the practical experience. Previous work by Bransford, Brown and Cocking (1999) showed that learning which can be assimilated in various contexts enables the student to develop a more flexible representation of that knowledge and thus an improved ability to draw upon that knowledge critically. This is arguably an essential skill for the Registered Nurse.

\section{Confidence and psychomotor proficiency}

Findings highlighted that students also view the practicum experience as an opportunity to practice and refine clinical skills. Six respondents $(26 \%)$ identified that practicing a skill gave them confidence in their ability to perform that skill. Existing barriers within the nursing clinical environment, such as the often frantic pace and skill-mix of the available staff, impacted upon the respondents' ability to receive the appropriate guidance and instruction from preceptors. This was highlighted by $48 \%$ of respon- 
Nursing students' perceptions of desirable leadership qualities in nurse preceptors

dents $(n=11)$ as an obtrusive factor to a positive learning experience within the clinical environment. Previous research by Polofroni et al. (1995) highlighted that although preceptored placements imply supervised and guided practice, students work without direct supervision for up to $75 \%$ of the time. This offers limited scope for development and constructive feedback on psychomotor skill development. When students feel secure with their preceptor and supported in their practice, they are more likely to ask questions and seek out learning opportunities (2004) which is also supported by findings from this study that suggest students are more likely to seek out a learning opportunity when paired with a preceptor who conveys interest and friendliness toward their student. This enhances not only their experience but their competence and confidence.

Findings from this study have reinforced previous research that demonstrated nurse preceptors exert significant influence over the practical experience of undergraduate nursing students in clinical placements (Cahill 1996; Dunn \& Hansford 1997; Lofmark \& Wikblad 2001). This study's findings also reveal that students unanimously agree that leadership is important in their nurse preceptors, and that the qualities of the effective nurse preceptor and the clinical leader are synonymous. These findings suggest that a good nurse preceptor is a clinical leader by definition of the role and its associated responsibilities.

In summary, findings showed that although effective clinical leaders were seen to be clinically competent and have a broad body of knowledge, they also demonstrated effective interpersonal skills. These skills, such as effective communication, compassion and supportive attitudes, are aspects of leadership that can be fostered from early on during undergraduate training. Equipping nursing students with the requisite foundation skills to think and behave as leaders from the outset, may head off the problems of apathy and resentment that exist when individuals are thrust into that position unwillingly. If attitudes and values can be shaped over the period of undergraduate education, then that behaviour becomes the norm and the natural behaviour that is modelled to the next generation.

Appropriate leadership training embedded within the undergraduate nursing program at all levels may be constructive. The model of leadership training adopted must be context specific for the nursing profession and be inclusive of strategies that are practical for students in early nurse education to adopt and assimilate into their developing skill set.

The theory-practice gap represents a challenge for new graduates and employers. One factor that has been shown to address the theory practice gap is continuity of preceptor during undergraduate clinical placements. While the current workforce demographic is not conducive to continuity, strategies to address the inconsistency experienced by students exposed to multiple nurse preceptors' warrants attention.

In addition to the preparation of students for preceptorship, nurse preceptors themselves need ongoing support and preparation for the role as a collaborative effort between healthcare organisations and tertiary education providers. The high turnover of staff in many areas of nursing both in clinical and education settings is a stark reality. Thus education related to the role and practical attributes of preceptors should reflect this. The researcher recommends preceptor training should be a mandatory competency for all nurses, particularly since it is cited by many nursing regulatory and professional organisations as a responsibility of the Registered Nurse (Australian Nursing and Midwifery Council 2005; NBWA 2004).

\section{LIMITATIONS}

The study was limited by a small sample size which impacts upon the generalisability of the results. However, trends and themes that emerged from the study offer directions for 
future research within this previously under researched area.

Although the purposive sample for the study was drawn from one tertiary institution, demographic data showed that the sample was generally representative of the local and Australia wide undergraduate nurse profile.

The instrument used for the study was newly developed and requires further development and more rigorous testing to assess clarity, apparent internal consistency, validity and reliability. Findings indicate it may have been advantageous to include an item asking respondents to provide a definition of the term 'preceptor'. Through the conduct of the study it became apparent there was considerable inconsistency in the application and definition of the term preceptor and its synonyms such as 'buddy-nurse', 'facilitator', 'practice-partner' and even inappropriate synonyms such as 'mentor'. Eliciting student meanings assigned to the terms may have been useful to clarify how students perceive and define the role.

\section{ConCLUSIONS}

This study sought to elicit undergraduate nursing students' perceptions of desirable leadership characteristics of their nurse preceptors. Nursing shortages are a global concern and are fuelled by factors such as an ageing existing workforce, recruitment and retention difficulties and attrition from pre-registration education programmes. It is an undisputed fact that there will always be a need for nurses and thus a need for high quality nursing education. The question of how the clinical nurse leaders of the future can be nurtured and prepared for their role in the current climate of instability is clearly of paramount importance.

Longitudinal research examining the impact of leadership training of nursing students and their transition to the workforce as graduates and preceptors would offer considerable insight to the further refinement of the nurse leader role. Findings may also impact on undergraduate nursing curricula.

Creating change and setting a course for a new direction in nursing education will require the collaborative effort of all the stakeholders to the profession. Believing in the capacity for change must become the underlying motivation to improve educational outcomes for pre-registration students. This can begin to be actualised through the construction of a critical mass of individuals willing to embrace and act as leaders of the profession.

\section{References}

Aamodt AA (1983) Problems in doing nursing research: Developing a criteria for evaluating qualitative research. Western Journal of Nursing Research 5(4): 398-402.

Alspach G (2006) Extending the synergy model to preceptorship: A preliminary proposal. Critical Care Nurse 26(2): 10-13.

Australian Health Workforce Advisory Committee (2004) The Australian nursing workforce - An overview of workforce planning 2001-2004. Retrieved 13 August 2006 from http://www.health.nsw .gov.au/amwac/pdf/nurseoview_20042.pdf

Australian Institute of Health and Welfare (2005) Nursing Labour Force 2003. AIHW Health Labour Force, 31. Canberra: AIHW.

Australian Institute of Health and Welfare (2003) Nursing Labour Force 2002. AIHW Health Labour Force, 30. Canberra: AIHW. Retrieved 1 May 2006, from http://www.anf.org.au/anf_pdf/ annual_report_2005.pdf

Australian Nursing and Midwifery Council (2005) Competency Standards for the Registered Nurse. Retrieved 17 September 2006 from http:// www.anmc.org.au/docs/Competency_ standards_RN.pdf

Australian Universities Teaching Committee (2002) Learning outcomes and curriculum development in major disciplines: Nursing. Adelaide: School of Nursing \& Midwifery.

Bass BM (1985) Leadership and performance beyond expectations. New York: The Free Press.

Bergeron CH (2002) Authentic leadership and a model of emergence. Unpublished Manuscript, The Bergeron Group. New Haven.

Bransford JD, Brown AL and Cocking RR (1999) 
How people learn: Brain, mind, experience and school. United States of America: National Academy of Science.

Burns JM (1978) Leadership. New York: Harper \& Row.

Cahill HA (1996) A qualitative analysis of student nurses' experiences of mentorship. Journal of Advanced Nursing 24(4): 791-799.

ChangingMinds (2006) Transactional leadership. Retrieved 21 May 2006, from http://changing minds.org/disciplines/leadership/styles/trans actional_leadership.htm

Clark D (1997) Concepts of leadership. Retrieved 10 April 2006 from http://www.nwlink.com / donclark/leader/leadchr.html

Clay MC, Lilley SH, Borre K and Harris JR (1999) Applying adult education principles to the design of a preceptor programme. Journal of Interprofessional Care 13(4): 405-413.

COGNOS (2006) Student Statistics. Perth, Western Australia: Edith Cowan University, Strategic Information Services.

Daly J, Speedy S and Jackson D (Eds) (2000) Contexts of nursing: An introduction. Sydney: MacLennan \& Petty.

De Pree M (1990) Leadership is an art. Melbourne: Australian Business Library.

Duignan P and Bhindi N (1997) Authenticity in leadership: an emerging perspective. Journal of Educational Administration 35(3): 195-209.

Dunn A (2003) Nurse shortage brings concern for patient care. The Age 8 May.

Dunn SV and Hansford B (1997) Undergraduate nursing students' perceptions of their clinical learning environment. Journal of Advanced Nursing 25(6): 1299-1306.

Firtko A, Stewart R and Knox N (2005) Understanding mentoring and preceptorship: Clarifying the quagmire. Contemporary Nurse 19(1): 32-34.

Geraghty SM (2005) How effective is preceptorship for midwifery students at a tertiary maternity hospital in WA? Unpublished Masters Dissertation, Curtin University of Technology, Perth, Western Australia.

Hekelman FP, Snyder CW, Alemagno S, Hull AL and Vanek EP (1995) Humanistic teaching attributes of primary care physicians. Teaching and Learning in Medicine 7(3): 29-36.

Hilliard J (2000) Communication skills are vital in all we do as educators and clinicians. Education for Health 13(2): 157-160.

Kerfoot K (2002) The synergy model in practice. Critical Care Nurse 22(2): 1-3.

Lett M (2001) The concept of clinical leadership. Contemporary Nurse 12(16): 16-21.

Lockwood-Rayermann S (2003) Preceptors, leadership style and the student practicum experience. Nurse Educator 28(6): 247-249.

Lofmark A and Wikblad K (2001) Facilitating and obstructing factors for development of learning in clinical practice: a student perspective. Journal of Advanced Nursing 34(1): 43-50.

Mahoney J (2001) Leadership skills for the 21st century. Journal of Nursing Management 9(5): 269-271.

Morrison RS, Jones L and Fuller B (1997) The relation between leadership style and empowerment on job satisfaction of nurses. Journal of Nursing Administration 27(5): 27-34.

Myrick F and Yonge O (2002) Preceptor behaviors integral to the promotion of student critical thinking. Journal for Nurses in Staff Development 18(3): 127-133.

National Nursing and Nursing Education Taskforce (2005) Scopes of practice commentary paper. Retrieved 18 May 2006 from http://www .nnnet.gov.au/downloads/n3et_sop_comment ary_paper_final.pdf

National Review of Nursing Education (2002) Nursing education and practice today. Canberra: Commonwealth of Australia.

Nurses Board of Western Australia (2004) Guidelines for preceptors and preceptorship in Western Australian nursing/midwifery. Retrieved 25 April 2006 from http://www.nbwa.org.au/2/23/50 /Guidelines.pm

Polofroni E, Packard S, Shah $\mathrm{H}$ and MacAvoy S (1995) Activities and interactions of baccalaureate nursing students in clinical practice. Journal of Professional Nursing 11(3): 161-169.

Sellers E and Deans C (1999) Nurse education in Australian Universities in a period of change: Expectations of nurse academics for the year 2005. Nurse Education Today 19(1): 53-61.

Sofarelli D and Brown D (1998) The need for nursing leadership in uncertain times. Journal of Nursing Management 6(4): 201-207.

Stanley D (2005) In command of care: Toward the 
theory of congruent leadership. Journal of Research in Nursing 11(2): 132-144.

Stanley D (2004) Clinical leaders in paediatric nursing: A pilot study. Paediatric Nursing 16(3): 39-42.

Stevenson K, Randle J and Grayling I (2006) Intergroup conflict in health care: UK students' experiences of bullying and the need for organisational solutions. The Online Journal of Issues in Nursing 11(2): 1-22.

Thyer GL (2003) Dare to be different: transformational leadership may hold the key to reducing the nursing shortage. Journal of Nursing Management 11(2): 73-79.

Tichy NM and Devanna MA (1990) The Transformational Leader. New York: John Wiley \& Sons.
Trofino J (1995) Transformational leadership in health care. Nursing Management 26(8): 42 47.

Usher K, Nolan C, Reser P, Owens J and Tollefson J (1999) An exploration of the preceptor role: preceptor's perceptions of benefits, rewards, supports and commitment to the preceptor role. Journal of Advanced Nursing 29(2): 506-514.

Vaughn LH and Baker RC (2004) Psychological size and distance: Emphasizing the interpersonal relationship as a pathway to optimal teaching and learning conditions. Medical Education 38(10): 1053-1061.

White R and Ewan C (1991) Clinical Teaching in Nursing. London: Chapman \& Hall.

\section{NOW AVAILABLE FROM ECONTENT}

The Leading Way of Changing Meaning by Sandra Sytsma

(ISBN 978-1-921214-26-4; ii+242 pages; 2007; Post Pressed; Institution: \$97.50; Individual: \$65.00) In studying leading as a way of changing meaning, this research documents a journey of inner exploration amongst five self-nominated leaders in education. In contrast to change limited by outer dimensional structure, changing meaning in an inner dimension was seen as the necessary complement in creating real difference in educators and in educating.

Over a period of almost a year, the leaders participated in an online project, travelling together through email dialogue focused around leading, changing and meaning. In this, they experiment with a changing way of researching. developing a personalised space of changing in which they could truth-test their thoughts and feelings about the multiple facts of leading and meaning. Such a space - interstitial to their outer working and inner personal lives, but deeply connective of both - was found useful in supporting coherent change processes in the participant leaders.

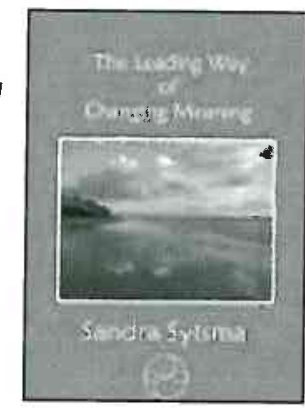

Awakening Struggle: Towards Buddhist Critical Social Theory by Robert Hattam (ISBN 978-1-876682-57-4; xx + 337 pages; 2004; Post Pressed; Institution: \$104.25; Individual: \$69.50)

'Awakening-Struggle demonstrates conceptual creativity through grappling with the foremost and advanced problems of contemporary critical theory. This work is a prodigious, scholarly account of critical theory that goes beyond the usual immanent reading and leads us to the 'affinity' between critical theory and Buddhism as a way of working towards a self-society dialectic that is a key to the critical theory tradition. Against critical theory's tendency towards social scientific objectivism that reinforces privilege in society, Hattam proposes Buddhist 'technologies of self' as resources for social activism and social revitalization.'

— Professor Philip Wexle (Hebrew University, Jerusalem)

eContent Management assumed exclusive distribution responsibility for PostPressed Academic Books from September 2007.

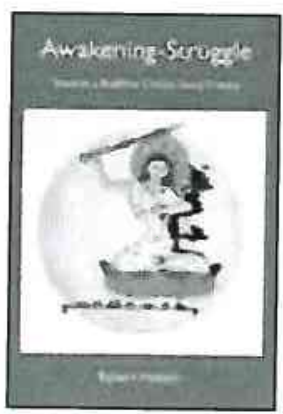

eContent Management Pty Ltd, PO Box 1027, Maleny QLD 4552, Australia Tel.: +61-7-5435-2900; Fax. +61-7-5435-2911 subscriptions@e-contentmanagement.com; www.e-contentmanagement.com 